\title{
Voltage regulation and power loss reduction by integration of SVC in distribution networks via PSSE
}

\author{
Ba-swaimi Saleh, Lee Jun Yin, Renuga Verayiah \\ College of Graduate Studies, Universiti Tenaga Nasional (UNITEN), Malaysia
}

\begin{tabular}{l} 
Article Info \\
\hline Article history: \\
Received Feb 7, 2020 \\
Revised Mar 6, 2020 \\
Accepted Apr 30, 2020 \\
\hline Keywords: \\
SVC (static VAR compensator) \\
Voltage stability \\
Loss reduction \\
DG (Distributed generation) \\
PSSE
\end{tabular}

\begin{abstract}
Voltage stability is necessary in order to maintain the health of the grid system. In recent years, the load demand is increasing from time-to-time which compromised the stability of the system. On that purpose, several methods on enhancing the voltage stability of the system was introduced such as the transformer tap and FACTS devices. In a general overview, this study is to propose a several power compensation techniques on the base case of an IEEE-33 bus whereby power flow analysis using NetwonRaphson in PSS/E software is performed. Afterwards, distributed generation (DG) and Static VAR Compensator (SVC) will be implemented within the distribution network to compensate the voltage instability losses based on the weakest index from the bus system. From both the cases which is proposed earlier, a comparison study is conducted on the performance on both DG and SVC within the proposed network.
\end{abstract}

This is an open access article under the $C$ C BY-SA license.

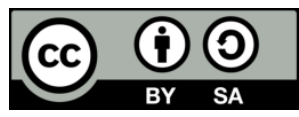

\section{Corresponding Author:}

Renuga Verayiah,

Department of Electrical Engineering,

Universiti Tenaga Nasional (UNITEN),

Putrajaya Compus, Jalan IKRAM-UNITEN, 43000 Kajang, Selangor, Malaysia.

Email: Renuga@uniten.edu.my

\section{INTRODUCTION}

Electricity plays an important role in the economic development of the country. All countries around the world looking for an affordable, reliable and secure supply of electricity to sustain modern ways of living. Power quality is always the top priority for the electrical utility to look on providing a continuous supply to their customers. The integration of distributed generators in the distribution network is increasing day by day [1] due to the protection of the environment from harmful emissions, technological advancement, energy crisis, power outages, technical issues, and economic incentives [2]. The intermittent nature of renewable energy sources will introduce many challenges to the power quality of the electricity supply [3]. The injected real power from DG tends to cause overvoltage or under voltage problems according to the penetration level of DG [3]. Distribution networks deliver electrical power to different load types i.e. industrial, commercial, residential, etc., those loads are subjected to fluctuate over a wide range and under heavy loading conditions, the distribution network will experience voltage instability $[4,5]$. Moreover, the majority of the increasing load is inductive in nature, which leads to a more lagging power factor of the system. The lagging power factor may increase the power loss in the network due to the high current drawing by the load and decrease the voltage profile of the network [2].

Voltage stability is essentially related to the reactive power balance [1], so by controlling reactive power between leading and lagging power factor can maintain the voltage within the acceptable voltage range and improve the reliability of the system. The conventional method in controlling the reactive power where power factor correction was fixed by the integration of fixed capacitors proving reactive power supply. 
The deployment of FACTS device within distribution network comes into effect in order to maintain the voltage level to be regulated within the index compensating reactive power [6]. Table 1 shows several types of FACTS device which are currently available in the market.

Table 1. Different types of FACTS device

\begin{tabular}{|c|c|c|c|}
\hline FACTS & Model of construction & Installation on & References \\
\hline $\begin{array}{l}\text { SVC - Static Var } \\
\text { Compensator }\end{array}$ & $\begin{array}{c}\text { Branches of two switches which consists of TCR (switched } \\
\text { inductor) and TSC (switched capacitor) }\end{array}$ & $\begin{array}{l}\text { Line or } \\
\text { buses }\end{array}$ & [7] \\
\hline $\begin{array}{l}\text { TCVR - Thyristor- } \\
\text { controlled voltage } \\
\quad \text { regulator }\end{array}$ & Power switches model of a tap changer & Line & {$[7,8]$} \\
\hline $\begin{array}{l}\text { STATCOM - Static } \\
\text { synchronous } \\
\text { compensator }\end{array}$ & $\begin{array}{l}\text { Energy storage superconducting magnetic storage (SMES) or } \\
\text { VSI with a DC link connected to a step-up transformer }\end{array}$ & $\begin{array}{l}\text { Line or } \\
\text { buses }\end{array}$ & {$[7,9-13]$} \\
\hline $\begin{array}{l}\text { UPFC - Unified power } \\
\text { flow controller }\end{array}$ & $\begin{array}{c}\text { Two transformer and power switches which acts as a rectifier and } \\
\text { compensated through control scheme and reverts back the DC } \\
\text { source to an AC waveform through an inverter }\end{array}$ & $\begin{array}{l}\text { Bus adjoint } \\
\text { with line }\end{array}$ & [14] \\
\hline
\end{tabular}

The fundamental of the device will be the same as the working principle of the transmission SVC whereby it will either inject or absorb reactive power to maintain the bus voltages to a certain level depending on the voltage regulation range of the end consumer. In the current market, SVC is still viable and being implemented within the transmission and distribution network as compared to the other FACTS devices. This is because the costing, maintenance and performance of the SVC technology is more feasible and matured to be applied whereby it requires smaller energy storage to perform any reactive compensations $[7,8]$. The drawback of the current SVC technology is due to its slow response time which leads to a slower compensation time compared to its successor [15-21].

\section{RESEARCH METHOD}

To find the optimal location of SVC and DG in IEEE 33-bus distribution network, three indices are used, which are the Voltage Stability Index (VSI), Voltage Stability Margin (VSM) and System Voltage Deviation (System VD). VSI from (1) is used to find the optimal location of DG. The value of VSI should be less than one. If VSI value closed to zero, then the system is more stable and vise versa. The bus with the highest VSI value is selected as the optimal location for DG [22]. VSM from (2) is used to find the optimal placement of SVC in a radial network [23]. VSM is an index used to find the margin stability of each bus and its value is between zero and one. The node with less VSM is closer to the collapse point and should be reinforced by injecting reactive power [22]. Voltage deviation in a system is defined as the difference between the nominal voltage and the actual bus voltage. The smaller the deviation of the voltage based on its nominal voltage, the better the voltage condition of the system. System Voltage Deviation (VD) is calculated using (3) [24, 25].

$$
V S I=\frac{4 X}{V_{1}^{2}}\left(\frac{P_{2}^{2}}{Q_{2}}+Q_{2}\right) \leq 1
$$

where,

$\mathrm{X}$ : Line reactance

$\mathrm{V}_{1}$ : Sending end bus voltage

$\mathrm{P}_{2}$ : Receiving end real power

$\mathrm{Q}_{2}$ : Receiving end reactive power

$$
\operatorname{VSM}(i)=V_{S}^{4}-4 V_{S}^{2}(R i P i+X i Q i)-4(R i P i+X i Q i)^{2} ; i=1,2 \ldots N
$$

where,

$\mathrm{X}_{\mathrm{i}}$ : Line reactance

$\mathrm{R}_{\mathrm{i}}$ : Line resistance

$\mathrm{V}_{\mathrm{s}}$ : Sending end bus voltage

$\mathrm{P}_{\mathrm{i}}$ : Receiving end real power

$\mathrm{Q}_{\mathrm{i}}$ : Receiving end reactive power 
$\mathrm{N}$ : Number of buses

$$
\text { System VD }=\sum_{1}^{n}\left(1-V_{n}\right)^{2}
$$

where,

$\mathrm{V}_{\mathrm{n}}$ : voltage magnitude of bus ' $\mathrm{n}$ ', expressed in (p.u.)

The IEEE 33-bus radial distribution network has 33 buses, 32-branch, 3 laterals, 5 tie switches, and one synchronous generator. The system-related voltage is $12.66 \mathrm{KV}$ with maximum and minimum limits of $\pm 5 \%$. The total real and reactive power loads are $3.715 \mathrm{MW}$ and $2.3 \mathrm{MVAR}$ connected to 32 buses with a different power factor [24]. The system data is taken from [4].

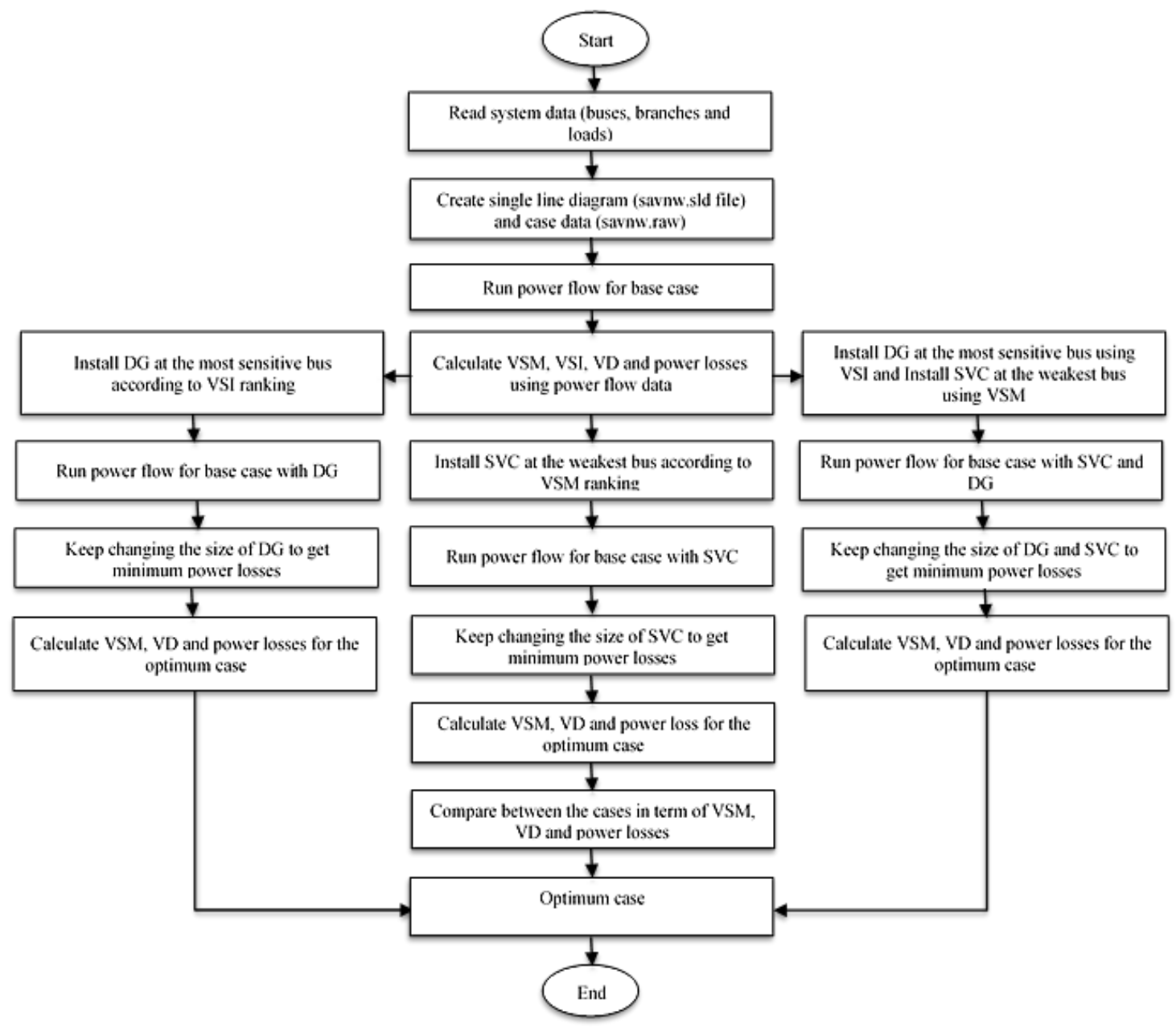

Figure 1. Flowchart of the research method

\section{RESULTS AND DISCUSSION}

The proposed method has been tested using PSS/E 34 software in the IEEE-33 bus distribution network. The comparison has been performed for four cases: Distribution network without SVC and DG, distribution network with SVC only, distribution network with DG only, and distribution network with both SVC and DG. The comparison is performed by taking into consideration of voltage stability margin (VSM), voltage deviation (VD) and real and reactive power losses.

\subsection{Case study 1: IEEE 33-bus system without SVC and DG}

The obtained results for real and reactive power losses are 202.65KW and 135.13KVAR respectively. The VSM and system VD are calculated for each bus using equation (2) and (3) respectively. The calculation results using load flow data showed that the 18th bus is the weakest bus with VSM of 0.695 and VD of 
$0.00755 \mathrm{pu}$. Figure 2 demonstrates the system voltage profile and VSM for the distribution network without SVC and DG.

\subsection{Case study 2: IEEE 33-bus system with SVC only}

The load flow analysis using fixed Newton -Raphson is conducted using PSSE to investigate the effect of SVC on the voltage profiles, VD and power losses of the network. SVC placed at an $18^{\text {th }}$ bus, which represents the lowest VSM in the system. The size of SVC is changed to get minimum VD with minimum power losses. From Table 2, it is observed that 0.5MVAR is the optimal size of SVC and the $18^{\text {th }}$ bus is the optimum place for the compensation. The placement of SVC is also tested at $33^{\text {th }}$ bus, which represented the lowest VSM in the second-longest lateral in the network. VSM and bus voltage profile with optimal placement of SVC at an $18^{\text {th }}$ bus is shown in Figure 3.

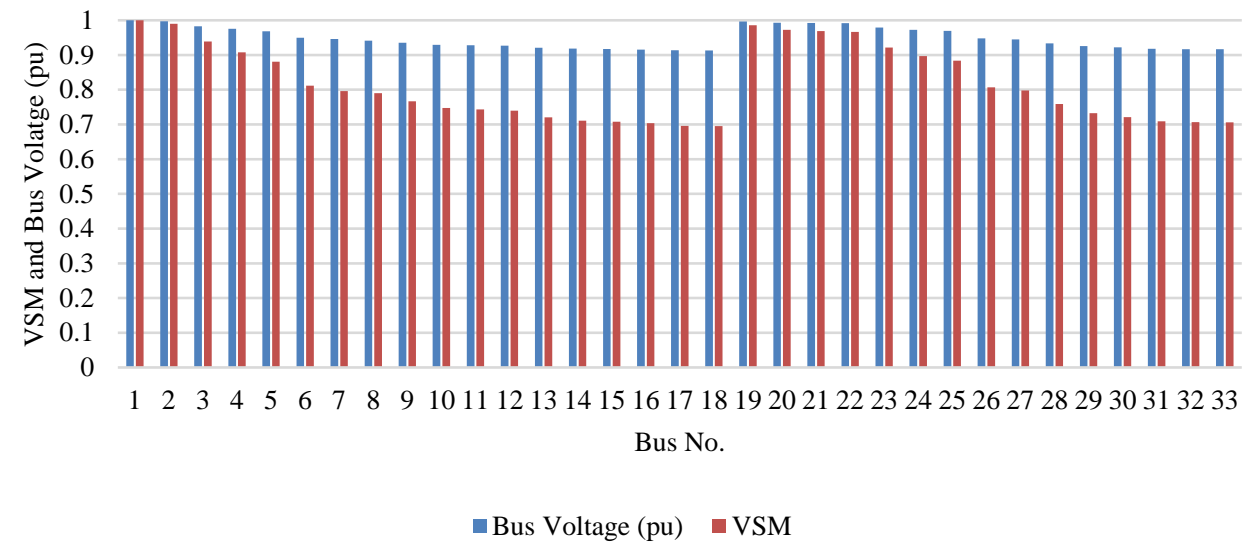

Figure 2. VSM and voltage profiles of network without SVC and DG

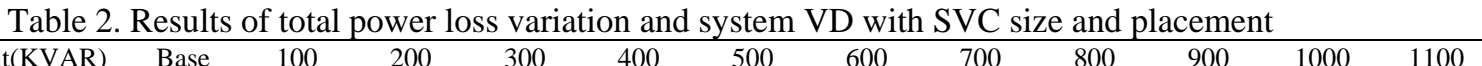

\begin{tabular}{ccccccccccccccc}
\hline $\begin{array}{l}\text { Bus } \\
\text { No. }\end{array}$ & Increment(KVAR) & $\begin{array}{c}\text { Base } \\
\text { case }\end{array}$ & 100 & 200 & 300 & 400 & 500 & 600 & 700 & 800 & 900 & 1000 & 1100 \\
\hline \multirow{3}{*}{18} & System VD (pu) & 0.117 & 0.110 & 0.100 & 0.097 & 0.091 & 0.086 & 0.081 & 0.076 & 0.071 & 0.062 & 0.059 & 0.055 \\
& Total KW loss & 202.65 & 195.87 & 190.73 & 186.69 & 183.98 & 182.62 & 182.68 & 184.19 & 187.21 & 197.93 & 205.78 & 215.31 \\
& Total KVAR loss & 135.13 & 130.49 & 127.13 & 124.7 & 123.35 & 123.13 & 124.07 & 126.2 & 129.58 & 140.22 & 147.51 & 156.23 \\
& System VD (pu) & 0.117 & 0.112 & 0.108 & 0.104 & 0.100 & 0.096 & 0.098 & 0.092 & 0.085 & 0.082 & 0.078 & 0.075 \\
33 & Total KW loss & 202.65 & 194.43 & 186.85 & 180.08 & 174.05 & 168.66 & 164.34 & 160.62 & 157.72 & 155.84 & 154.69 & 154.41 \\
& Total KVAR loss & 135.13 & 129.48 & 124.36 & 119.87 & 116 & 112.65 & 110.12 & 108.12 & 106.78 & 106.21 & 106.26 & 107.02 \\
\hline
\end{tabular}

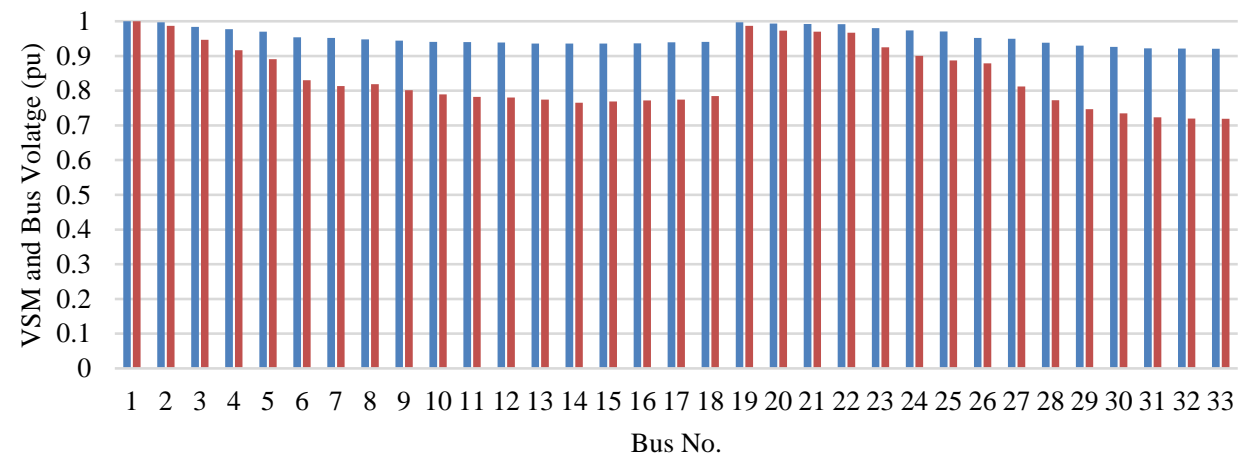

Bus Voltage $\quad$ VSM

Figure 3. VSM and voltage profiles of network with SVC only 


\subsection{Case study 3: IEEE 33-bus system with DG only}

The load flow analysis using fixed Newton -Raphson is conducted using PSSE to investigate the effect of DG at unity power factor on the voltage profiles, system VD and power losses of the network. DG placed at $6^{\text {th }}$ bus according to VSI, which is calculated using the proposed method in [18] using Equation (2).The data for calculating VSI are obtained from load flow result using Newton-Raphson in PSSE. The size of DG is changed in steps in order to get minimum VD with minimum power losses. From Figure 4 and 5 it is observed that $2.6 \mathrm{MW}$ is the optimal size of DG and $6^{\text {th }}$ bus is the optimal location for DG placement with system VD of 0.0290 pu. Figure 6 shows the impact of opimal placement of DG in VSM and voltage profile of the network.

\subsection{Case study 4: IEEE 33-bus system with both SVC and DG}

The optimal sizes of SVC and DG are the same as installing individually, which are 0.5MVR for SVC and 2.6MW for DG. The greatest improvement for voltage profiles is made with the installation of both SVC and DG as shown in Figure 7. It is observed that all buses of the system are within the acceptable limit considering $\pm 5 \%$ around the related voltage as shown in Figure 8 . The VSM of the current system are acceptable as all of its buses are close to 1 which is shown in Figure 9. The reduction in real and reactive power losses with the integrated SVC and DG within the bus system are $85.78 \mathrm{KW}$ and $64.26 \mathrm{KVAR}$ as indicated in Table. To compare with the other previous mentioned system earlier, both SVC and DG contributes significantly in power losses reduction. By performing voltage deviation using Equation (3), the voltage deviation is obtained at a value of 0.0147 p.u. Based on the obtained deviation, the voltage condition in the system is favourable as the difference between the nominal voltage with the current bus voltage is relatively small.

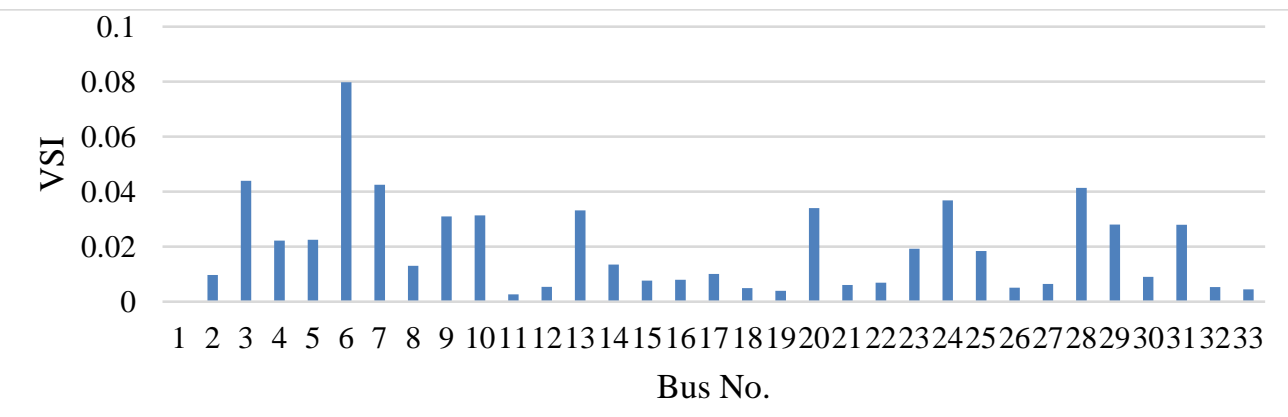

Figure 4. VSI profiles of IEEE 33 radial distribution network

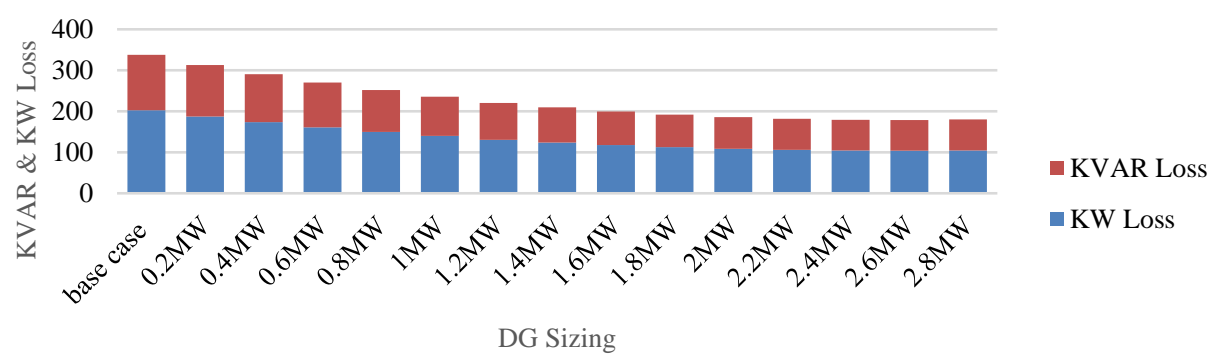

Figure 5. Results of total power losses variation with DG size 


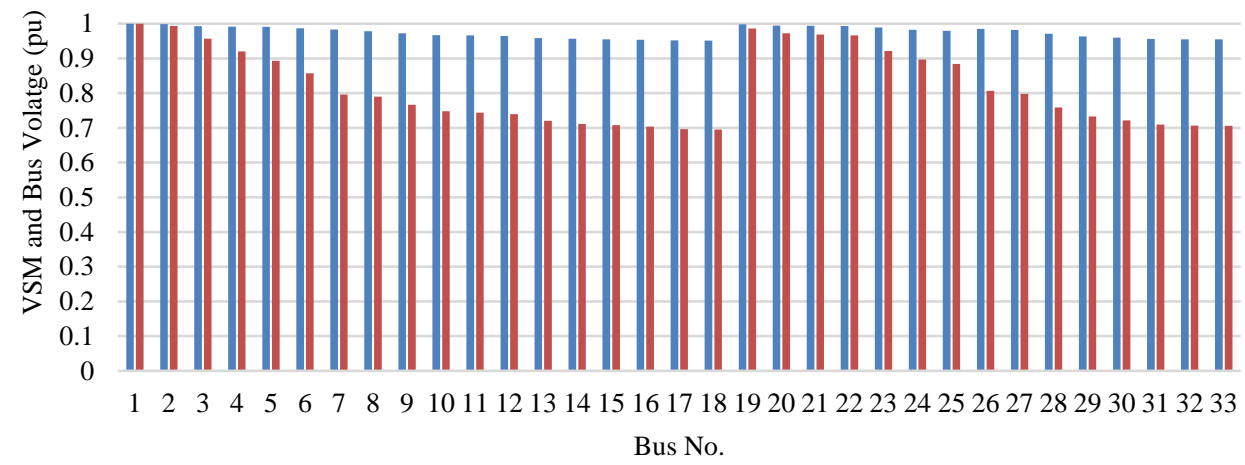

- Bus Voltage $\quad$ VSM

Figure 6. VSM and voltage profiles of network with DG only

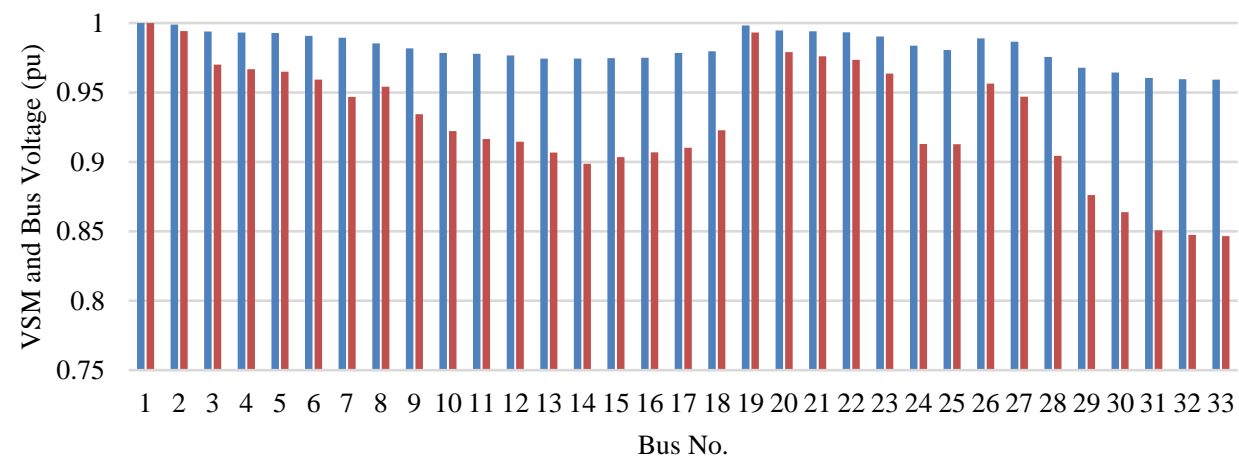

• Bus Voltage (pu) $\quad$ VSM

Figure 7. VSM and voltage profiles of network with both SVC and DG

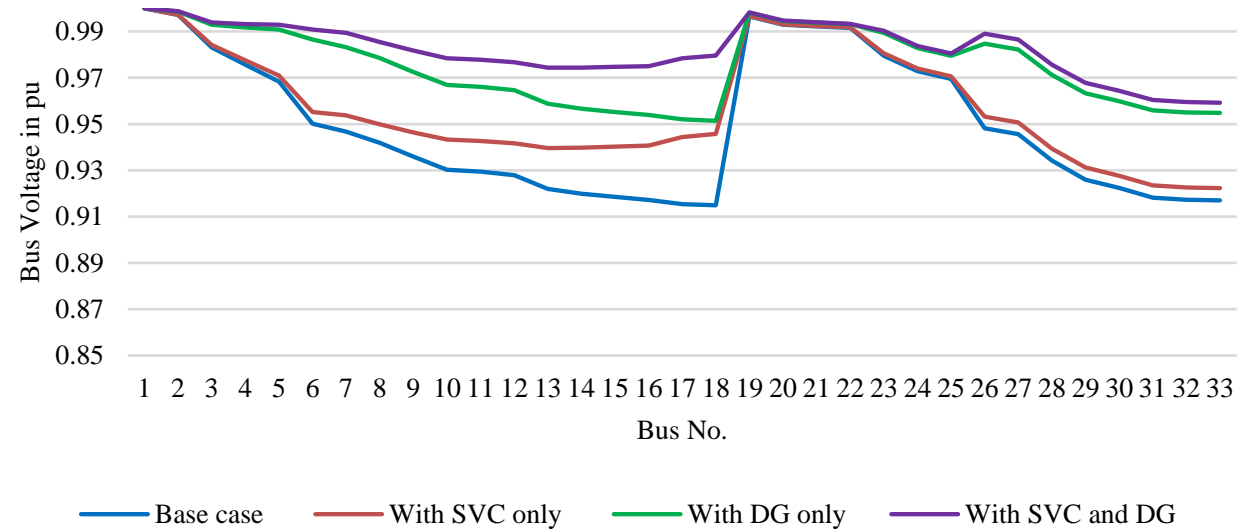

Figure 8. Comparison between all the results of voltage profile of IEEE-33 bus system without and with SVC and DG 


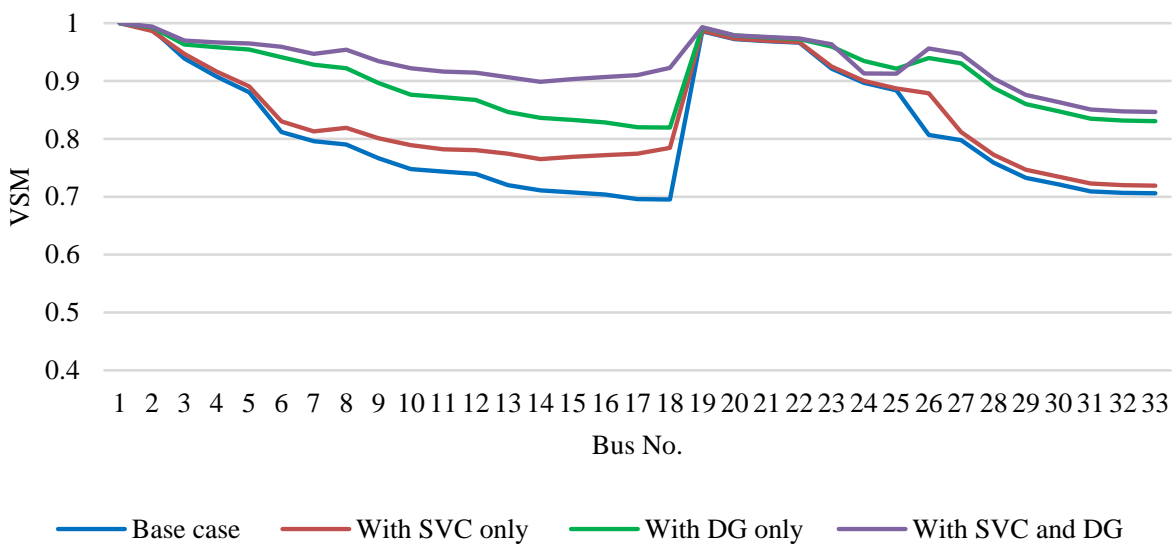

Figure 9. Comparison between all the results of VSM of IEEE-33 bus system without and with SVC and DG

Table 3. Comparison analysis of IEEE-33 bus system with and without SVC and/or DG

\begin{tabular}{ccccc}
\hline Description & Base Case & With SVC only & With DG only & With SVC and DG \\
\hline SVC size(MVAR) & - & 0.5 & - & 0.5 \\
SVC location & - & 18 & - & 18 \\
DG size(MW) & - & - & 2.6 & 2.6 \\
DG location & - & - & 6 & 6 \\
System VD(pu) & 0.117 & 0.863 & 0.029 & 0.0147 \\
Total real power loss(KW) & 202.65 & 182.62 & 103.97 & 85.78 \\
Total reactive power loss(KVAR) & 135.13 & 123.13 & 74.83 & 64.26 \\
Minimum bus voltage(pu)@bus & $0.913 @ 18$ & $0.920 @ 33$ & $0.9514 @ 18$ & $0.959 @ 33$ \\
Minimum VSM @ bus & $0.695 @ 18$ & $0.819 @ 33$ & $0.9514 @ 18$ & $0.846 @ 33$
\end{tabular}

\section{CONCLUSION}

In this work, SVC integration in IEEE 33-bus distribution system is investigated using PSSE software. The objectives are to improve voltage profile and reduce network power losses. The investigation is performed for SVC in a radial distribution network with and without DG. The best location for SVC and DG are identified using VSM and VSI, respectively. Simulation results show that SVC with DG is the best case for improving voltage profile and reducing power losses in the network. The installation of SVC with the size of 0.5MVAR improved voltage profiles and reduced the losses. The sizing and types of DG sources should be planned wisely especially having PV as one of the selections due to the inconsistent generation which may eventually lead to other power quality issues such as voltage sag/swell. Future research might introduce multiple SVC placement in the distribution network and using optimization techniques for SVC sizing and placement.

\section{ACKNOWLEDGEMENTS}

The authors gratefully acknowledge Universiti Tenaga Nasional for the financial support through UNITEN internal grant UNIIG 2018 to conduct this research project.

\section{REFERENCES}

[1] K. Chakraborty, G. Deb and S. Deb, "Voltage stability assessment in radial distribution system by line stability indicator (LSI) and its improvement using SVC," 2016 IEEE 1st International Conference on Power Electronics, Intelligent Control and Energy Systems (ICPEICES), Delhi, 2016, pp. 1-5.

[2] F. Iqbal, M. T. Khan, and A. S. Siddiqui, "Optimal placement of DG and DSTATCOM for loss reduction and voltage profile improvement," Alexandria Engineering Journal, vol. 57, no. 2, pp. 755-765, 2018.

[3] M. M. Hussein and K. Mahmoud, "Combined static VAR compensator and PV-inverter for regulating voltage in distribution systems," 2017 Nineteenth International Middle East Power Systems Conference (MEPCON), pp. 19$21,2017$.

[4] Z. G. Sanchez, J. A. G. C. Cruz, G. C. Sanchez, H. H. Herrera, and J. I. S. Ortega, "Voltage collapse point evaluation considering the load dependence in a power system stability problem," International Journal of Electrical and Computer Engineering (IJECE), vol. 10, no. 1, pp. 61-71, 2020. 
[5] B. Singh and G. Agrawal, "Enhancement of voltage profile by incorporation of SVC in power system networks by using optimal load flow method in MATLAB/Simulink environments," Energy Reports, vol. 4, pp. 418-434, 2018.

[6] M. Simeon, W. S. Tita, I. A. Adejumobi, and A. Elizabeth, "Minimization of Active Transmission Loss in Power Systems using Static Var Compensator," International Journal of Applied Engineering Research, vol. 13, no. 7, pp. 4951-4959, 2018.

[7] E. Ghahremani and I. Kamwa, "Analysing the effects of different types of FACTS devices on the steady-state performance of the Hydro-Québec network," IET Generation, Transmission \& Distribution, vol. 8, no. 2, pp. 233 249, 2014.

[8] M. Zellagui, H. A. Hassan, and A. Chaghi, "Effect of TCVR controlled voltage on short-circuit calculations in case of ground fault in the Algerian network," International Journal of Control and Automation, vol. 8, no. 1, pp. 125$138,2015$.

[9] O. K. Shinde and V. R. S. V. B. Pulavarthi, "STATCOM converters and control: A review," 2017 Int. Conf. Data Manag. Anal. Innov. ICDMAI 2017, pp. 145-151, 2017.

[10] A. Saha, S. Ahmad, A. A. Soma, M. Z. A. Chowdhury, and A. A. Hossain, "Modelling and control of STATCOM to ensure stable power system operation," 4th Int. Conf. Adv. Electr. Eng. ICAEE 2017, pp. 12-17, 2018.

[11] Z. Xinwen and T. Xiangqian, "Topology and control study for a novel STATCOM," in 2016 Chinese Control and Decision Conference (CCDC), 2016, pp. 1235-1240.

[12] N. Cherkaoui, T. Haidi, A. Belfqih, F. El Mariami, and J. Boukherouaa, "A Comparison Study of Reactive Power Control Strategies in Wind Farms with SVC and STATCOM," International Journal of Electrical and Computer Engineering (IJECE), vol. 8, no. 6, pp. 4836-4846, 2018.

[13] M. A. Kamarposhti and M. Alinezhad, "Comparison of SVC and STATCOM in Static Voltage Stability Margin Enhancement," World Academy of Science, Engineering and Technology, pp. 860-865, 2009.

[14] Parvathy S. and K. C. S. Thampatty, "Dynamic Modeling and Control of UPFC for Power Flow Control," Procedia Technology, vol. 21, pp. 581-588, 2015.

[15] A. Qatamin et al., "SVC versus STATCOM for improving power system loadability: A case study," 2017 8th Int. Renew. Energy Congr. IREC 2017, pp. 1-4, 2017.

[16] I. Alhamrouni, R. Ismail, M. Salem, B. Ismail, A. Jusoh, and T. Sutikno, "Integration of STATCOM and ESS for power system stability improvement," International Journal of Power Electronics and Drive System (IJPEDS), vol. 11, no. 2, pp. 868-878, 2020.

[17] W. N. Chang and C. H. Liao, "Design and implementation of a statcom based on a multilevel FHB converter with delta-connected configuration for unbalanced load compensation," Energies, vol. 10, no. 7, 2017.

[18] E. Barrios-martínez and C. Ángeles-camacho, "Technical comparison of FACTS controllers in parallel connection," Journal of applied research and technology, vol. 15, no. 1, pp. 36-44, 2017.

[19] L. Xu, L. Yao, and C. Sasse, "Comparison of Using SVC and STATCOM for Wind Farm Integration," in 2006 International Conference on Power System Technology, 2006.

[20] Q. Zhang, H. Liu, Y. Bai, J. Wang, and Y. Qu, "A Novel Analysis Scheme for Static Voltage Stability of Distribution Network with DFIG and SVC," 2018 IEEE 3rd Adv. Inf. Technol. Electron. Autom. Control Conf., pp. 201-206, 2018.

[21] M. Zamani-gargari, F. Kalavani, and K. Zare, "Review of Impacts of Static Var Compensator Allocation on Radial Distribution Networks," IETE Journal of Research, vol. 65, no. 1, pp. 120-127, 2019.

[22] B. Pati and S. B. Karajgi, "Optimized placement of multiple FACTS devices using PSO and CSA algorithms," International Journal of Electrical and Computer Engineering (IJECE), vol. 10, no. 4, pp. 3350-3357, 2020.

[23] V. V. S. N. Murty and A. Kumar, "Optimal placement of DG in radial distribution systems based on new voltage stability index under load growth International Journal of Power Electronics and Drive System (IJPEDS), vol. 69, pp. 246-256, 2015.

[24] V. Vita, "Development of a decision-making algorithm for the optimum size and placement of distributed generation units in distribution networks," Energies, vol. 10, no. 9, 2017.

[25] T. P. Nguyen and D. N. Vo, "A novel stochastic fractal search algorithm for optimal allocation of distributed generators in radial distribution systems," Appl. Soft Comput., vol. 70, pp. 773-796, 2018. 


\section{BIOGRAPHIES OF AUTHORS}

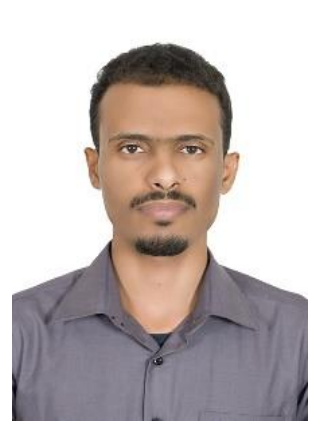

Ba-swaimi Saleh was born in Hadhramout, Yemen, in 1991. He received the B.Sc. degree in electronic and communication engineering from Hadhramout University (Engineering College), Yemen, in 2015. He is currently pursuing the M.E degree in electrical engineering (Power Systems) at Universiti Tenaga Nasional (UNITEN), Selangor, Malaysia. His research interests include voltage stability of distribution systems and renewable energy integration.

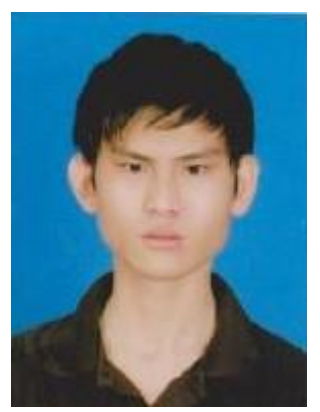

Lee Jun Yin was born in Ipoh, Perak. He received his Diploma from Politeknik Ungku Omar in 2016 and B. Eng Degree in UNITEN in 2019. He is currently a postgraduate student pursuing his Masters in Universiti Tenaga Nasional (UNITEN). His main research area includes Power System Studies, Control System and Intelligent Controllers.

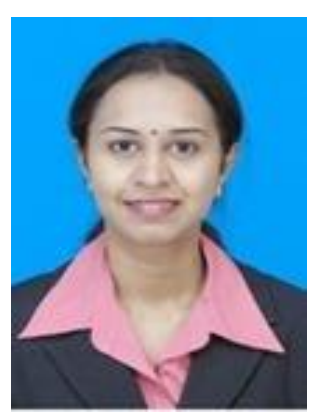

Renuga Verayiah received her Bachelor of Electrical \& Electronics Engineering Degree in 2002 and Master of Electrical Engineering in 2007 from the University Tenaga Nasional, Malaysia. She obtained her PhD degree in Electrical, Electronics \& System Engineering in 2017 from Universiti Kebangsaan Malaysia, Malaysia. Renuga is currently serving as a senior lecturer at Department of Electrical \& Electronics Engineering, UNITEN and as a Program Coordinator for Master of Electrical Engineering Program at College of Graduate Studies, UNITEN. She is a member of Institute of Engineering and Technology UK (MIET) and The Institution of Engineers Malaysia (IEM). She is also a Certified Energy Manager, Certified Professional in Measurement and Verification, and a technical working committee for country's National GHG inventory and International Consultation \& Analysis (ICA) (BUR2) Malaysia. Her research interest includes power system steady state analysis, power system dynamic analysis, and power system optimization. 